\title{
Considerações sobre trabalho educativo-preventivo a nível comunitário
}

\author{
Moreira, Suzana Gomes * \\ Hahn, Marlê A. S. *
}

\begin{abstract}
RESUMO
As autoras tecem consideraçōes que subsidiam o desenvolvimento de açōes de promoção de saúde junto a crianças com

idade pré-escolar e alunos da rede escolar de ensino público e de instituiçōes públicas ou filantrópicas. Colocam a importância do conhecimento prévio da realidade da vida das pessoas para dar início ao processo de planejamento do trabalho educativo-preventivo bem como a implementação das açōes pertinentes.
\end{abstract}

\section{SUMMARY}

\begin{abstract}
The authors make considerations to subsidize the planning and development of health promoting actions to pre-school and school children of public school and philanthropy institutions. They stress the importance of previous understandig the community's way of life for planning their attendance by educational and preventive means as well as the use of relevant actions.
\end{abstract}

\section{Introdução}

Para viabilização da alteração do perfil de morbidade odontológica vigente na população brasileira tornase imperiosa a mudança ou substituição de modelo da prática odontológica dominante na atualidade, que fundamenta-se no tratamento das sequelas das doenças mais prevalentes na boca (cárie e doença periodontal inflamatória) $(5,6)$.

É de vital importância e significado que as açōes odontológicas desenvolvidas ou implementadas pelos serviços públicos de saúde passem a priorizar ou previlegiar os procedimentos e atividades vinculadas ao que se costuma chamar de "promoção de saúde" para a obtenção da higiene bucal e sua preservação ou manutençăo. Apenas dessa forma será possível, a médio o longo prazo a reversão do atual quadro sanitário.

Neste artigo tecer-se-ăo consideraçōes sobre a implementação de trabalho educativo-preventivo visando a promoção de saúde, no que tange a caracterização da clientela e o processo de planejamento, válidas tanto para a comunidade escolar como para a de instituiçōes de caráter público ou filantrópico.

\section{Caracterização da comunidade}

É necessário e fundamental o conhecimento prévio da realidade da comunidade com a qual se pretende trabalhar. Para tal, precisa-se encetar um processo de caracterização da comunidade ou população ou escola ou instituição que embasará um outro processo, o de planejamento do trabalho a nível comunitário, que é dinâmico e que deve guardar especificidade com a clientela a que se destina $(1,4)$.

Vários aspectos ligados ao funcionamento da instituição devem ser considerados quando se procede o conhecimento da realidade local, tais como: o tipo de gerência e natureza da administraçăo; características da população (o número de pessoas, a faixa etária, existência de grupos e quantidade, população envolvida, tais como funcionários, professores, diretores, etc.); rotina da instituição; horário de funcionamento; disponibilidade de tempo para trabalho na área da saúde; etc.

Informações sobre as condiçōes de vida da população a ser envolvida no trabalho são extremamente úteis e necessárias e possibilitam uma compreensão maior da dimensão e limites do trabalho a ser implantado. Neste item, se incluem dados sobre a vida familiar das crianças, renda familiar, nível de escolaridade, ocupação, constituição da estrutura familiar, etc., muitas vezes constantes no fichário da instituição/escola.

Os aspectos culturais da comuni- dade, com visão de mundo, valores, forma de encarar o processo saúúdedoença, os hábitos individuais e familiares relacionados a saúde merecem especial atenção por parte do grupo que pretende, efetivamente, dar o início a um trabalho consequente. Com isto pode-se evitar o erro de subestimar ou menosprezar o conhecimento popular o que muitas vezes pode levar ao fracasso as tentativas nessa área.

O conhecimento do tipo de experiências de trabalhos vinculados a saúde anteriormente desenvolvidos na instituiçăo ou com a clientela possibilita uma avaliação mais aproximada e uma compreensão do contexto ou conjuntura em que se vai atuar.

Nessa linha, é importante identificar tanto a época como o seu período de duração, as pessoas que participaram ou envolveram-se no trabaIho, as ações realizadas e principalmente como o pessoal da escola/instituição avalia ou considera os trabaIhos desenvolvidos nessas ocasiōes.

O conhecimento do que foi aprendido nessas experiências anteriores pelas crianças e comunidade em

\footnotetext{
* Professora Adjunta do Departamento de Odontologia Preventiva e Social da Faculdade de Odontologia da UFRGS

** Professora Assistente do Departamento de Odontologia Preventiva da Faculdade de Odontologia da Pontifícia

Universidade Católica do Rio Grande do Sul
} 
relação a saúde bucal; de qual a expectativa que o corpo docente, funcionários, pais ou responsáveis pelas crianças têm em relação a trabalhos na área da saúde e, especialmente, qual a expectativa das crianças (clientela específica), propiciará um planejamento mais adequado e com possibilidades maiores de obtenção de eficácia dos propósitos colocados inicialmente.

\section{Trabalho educativo- preventivo e o processo de planejamento}

Considerando-se que o conhecimento profundo e minucioso da realidade é condição essencial para que se possa planejar um programa de saúde bucal adequado e coerente, é preciso que os técnicos em saúde tenham presente que, antes dè se "jogar receitas e prescrições" para prevenir doenças e promover saúde, é necessário conhecer as condiçōes efetivas de vida da comunidade em termos sociais, econômicos e financeiros bem como o que ela sabe sobre 0 assunto como também quais experiências, intervençōes que ela foi submetida anteriormente. Esta visão e conhecimento da realidade permitirá o desenvolvimento de um programa mais exequível e até certo ponto flexível, no sentido de, no enfrentamento de obstáculos, não cair no imobilismo, mas instigar a elaboração de novas estratégias.

Um outro aspecto de grande importância e que deve ser considerado neste momento é o que se refere a trabalho multiprofissional na área da saúde. Neste sentido, se faz necessário que os cirurgiōes-dentistas, bem como o pessoal auxiliar odontológico responsáveis pela Saúde Bucal da população criem condiçōes para o desenvolvimento de um programa de saúde integrado, juntamente com outros profissonais que já atuam ou que possam vir a atuar no local, como médicos, psicólogos, enfermeiras, assistentes sociais, nutricionistas, etc... Esta necessidade parte do princípio que saúde-doença é um processo dinâmico bio-psicosocial (8) que nảo pode nem deve ser entendido e muito menos trabaIhado de forma fragmentada e compartimentalizada em "especialidades", como tradicionalmente tem sido feito.

Somente após ter-se pleno conhecimento das ações anteriormente de- senvolvidas na comunidade e principalmente, após a familiarização com a vida da instituição e/ou clientela mediante a sua caracterização, contatos com o pessoal envolvido e pertencente a comunidade e tendo-se procedido a elaboração de um plano de trabalho participativo é que pode-se tomar as providências necessárias para o desenvolvimento das açōes preventivas/educativas ou de promoção de saúde. De posse de todas essas informaçōes acerca da realidade da comunidade, a viabilidade de desenvolvimento do trabaIho é maior. Podendo-se, então, junto com a comunidade para a definição de:

- População a ser envolvida no trabalho.

- Classificação das crianças/pessoas em função de suas condições de saúde.

- Prioridades.

- Atividades ou ações a serem desenvolvidas.

- Grau de participação e natureza do envolvimento da comunidade na realização do trabalho.

- Formas de avaliação.

Considera-se que cada um dos ítens acima mencionados devem ser avaliados com atenção, considerando-se inclusive o tempo, recursos humanos, materiais e espaços disponiveis.

Todo o conjunto de ações a implementar-se visando a promoção da saúde deve ser planejado. Porém, o que significa planejar um trabalho educativo/preventivo consequente, eficaz e de continuidade a nível de uma escola ou comunidade?

Significa o envolvimento, em todo o trabalho a ser desenvolvido, do maior número de pessoas além dos técnicos de saúde, oriundas ou pertencentes a comunidade (neste caso, a direção, a instituição, profesores, funcionários, círculos de Pais e Mestres, mães, cidadãos, etc.). Deve-se buscar a participação ativa das pessoas, que não técnicos, durante o período o processo tanto de deliberaçōes como de tomada de decisőes. Quando a opinião e o posicionamento da comunidade são considerados e subsidiam a proposta de trabalho, existem maiores possibilidades do mesmo realizar-se sem atropelos e com maior tranquilidade. Evidentemente que as questões técnicas, embasadas pelo saber científico acumulado e atualizado, colocadas pelos profissionais de saúde são de relevância e pre- ponderância e devem ser transferidas e compreendidas pela população. A comunidade deve participar de todo o processo, ou seja, do que fazer, como fazer e por que fazer, e năo limitar-se apenas a ouvintes e pacientes daquilo que os técnicos decidiram ou acharam melhor desenvolver.

Torna-se necessário o estabelecimento de uma relação dialógica $(2,3)$ com a comunidade, ou seja, de troca de experiências e conhecimentos, o que possibilita o crescimento e enriquecimento bilateral necessário ao desenvolvimento do trabalho.

Este tipo de relaçāo poderá propiciar à comunidade a compreensāo do processo saúde-doença em sua totalidade e em seus determinantes, promovendo, simulataneamente, o desvelamento da realidade, bem como a redescoberta do seu corpo $(2,3,8)$. Possibilitará a consciência das formas básicas de prevenção e controle das doenças da placa, que se constituem da reduçāo ou eliminação do consumo do açúcar refinado, remoção mecânica da placa e o uso do flúor em suas diversas formas (7).

Resumindo, o planejamento deve constituir-se em um trabalho conjunto e participativo. É importante salientar que o Planejamento é um processo dinâmico, devendo estar continuamente sendo reavaliado e deve apresentar uma especificidade com relação as realidades observadas em cada comunidade. Ou seja, deve ser adequado a população com que se está trabalhando.

REFERÊNCIAS BIBLIOGRÁFICAS

1. Associaçāo de Educaçāo Católica do Brasil. Planejamento: educando para a participaçāo - Revista de Educaçāo AEC - ano 19, n० 75. Abril/junho 1990

2. FREIRE, Paulo. Educaçāo e Mudança. Trad. Moacir Gadotti e Lilian Lopes Martin RJ. Paz e Terra. 1979. Coleçäo Educaçāo e Comunicaçāo. vol. 1.79p

3. -. Pedagogia do Oprimido. $5^{a}$ ed. RJ. Paz e Terra. 1978. 220p.

4. GANDIM, Danilo. Planejamento como Prática Educativa. Ed. Loyola, Sāo Paulo, 1985.

5. MENDES, Eugênio Vilaça. A evoluçāo histórica da prática médica - notas preliminares. Belo Horizonte, 1980. "mimeo". $59 p$.

6. MENDES, Eugênio Vilaça. A Reforma Sanitária e a Educaçāo Ôdontológica. Cadernos de Saúde Pública. RJ 2 (4):

7. THYLSTRUP, Anders \& FEJERSKOV, Ole. Tratado de Odontologia. Trad. Lood. Sérgio Weyne - RJ: Cultura Médica.

8. REZENDE, Ana Lúcia Magda de. Saúde: dialética do pensar e do fazer. São Paulo: Cortez. 1986. 